\title{
Pandemia de Covid-19 e a saúde dos refugiados no Brasil*
}

\section{| ${ }^{1}$ Igor de Assis Rodrigues, ${ }^{2}$ João Roberto Cavalcante, ${ }^{3}$ Eduardo Faerstein I}

\begin{abstract}
${ }^{1}$ Instituto de Medicina Social, Universidade do Estado do Rio de Janeiro. Rio de Janeiro-RJ, Brasil (rodriguesidea@gmail.com). ORCID: 0000 0002-1030-1101

2 Instituto de Medicina Social, Universidade do Estado do Rio de Janeiro. Rio de Janeiro-RJ, Brasil (joao.rcs@hotmail.com). ORCID: 00000003-2070-3822

${ }^{3}$ Instituto de Medicina Social, Universidade do Estado do Rio de Janeiro. Rio de Janeiro-RJ, Brasil (efaerstein@gmail.com). ORCID: 00000002-4027-4896
\end{abstract}

Recebido em: 08/06/2020

Aprovado em: 14/06/2020

Revisado em: 20/06/2020

\section{Contextualização}

O início da transmissão de Covid-19 foi notificado pela China à Organização Mundial da Saúde (OMS) pela primeira vez em 31 de dezembro de 2019. A OMS, após reunião do Comitê de Emergência, declarou Emergência de Saúde Pública de Importância Internacional em 30 de janeiro de 2020, e pandemia em 11 de março de 2020 (OMS, 2020a). O Brasil, por sua vez, declarou Emergência de Saúde Pública de Importância Nacional (ESPIN) por Covid-19 em 3 de fevereiro de 2020 (BRASIL, 2020a). Até $1^{\circ}$ de junho de 2020, foram registrados 6.057 .853 casos e 371.166 óbitos (letalidade de 6,12\%) em 216 países e territórios (OMS, 2020a), sendo no Brasil 526.447 casos e 29.937 óbitos (letalidade de 5,68\%) (BRASIL, 2020b).

Durante outras emergências internacionais, como a de síndrome congênita pelo zika (2015-2016) e as de ebola (2014-2016 e 2018-2020), a transmissão dessas doenças estava intimamente ligada aos locais de moradia e questôes sociais e culturais

\footnotetext{
* Os autores agradecem a Francisco Ortega, professor titular do Instituto de Medicina Social da UERJ, por sua contribuição fundamental na elaboração deste comentário.
} 
(CAVALCANTE; SCHUTZ, 2016; FREITAS et al., 2019). Atualmente, existe tanto no Brasil quanto em países do sul e norte global uma preocupação maior sobre a disseminação de Covid-19 em comunidades pobres e vulneráveis. A subnotificação e a deficitária divulgação de dados desagregados sobre a propagação da pandemia de Covid-19 entre essas populaçôes, bem como as desigualdades e especificidades culturais desses grupos, acendem mais um alerta da importância desse debate. Historicamente, essas populaçóes possuem dificuldades de acesso aos serviços de saúde e, especificamente nos contextos urbanos, apresentam números mais altos de habitantes por domicílio que populaçôes de classe média ou classe média alta estando, portanto, em maior risco durante a pandemia (KENNEDY et al., 2020).

Um editorial recente da revista The Lancet recomenda que cada sociedade identifique e dê suporte aos grupos considerados mais vulneráveis. Se esses grupos não são devidamente identificados e assistidos, as consequências da pandemia serão mais devastadoras, levando ao aprofundamento das desigualdades em saúde (EDITORIAL, 2020a). No Brasil, pessoas em situação de rua, com sofrimento ou transtorno mental, com deficiência, vivendo com HIV/aids, LGBTI+, população indígena, negra e ribeirinha, migrantes forçados, trabalhadores do mercado informal, como catadores de materiais recicláveis, artesãos, camelôs, prostitutas e população privada de liberdade se encontram em situação de extrema vulnerabilidade frente à Covid-19.

\section{Migraçóes forçadas e pandemia}

Os migrantes forçados são indivíduos que, por motivos diversos, abandonam de maneira involuntária suas localidades de origem. Conflitos, guerras, desequilíbrios socioeconômicos, violência, pobreza, fome, exploração, epidemias e busca por acesso à saúde constituem os principais motivos da migração (MILESI, 2005). Entre os migrantes forçados, destacam-se os refugiados: indivíduos que se deslocaram para outro país e não podem ou não querem retornar em virtude de fundado temor de perseguição por raça, religião, nacionalidade, grupo social, opiniôes políticas (ACNUR, 1967) ou situação de grave e generalizada violação de direitos humanos em seu país de origem (MILESI, 2005). Os dados mais recentes disponíveis apontam que 70,8 milhóes de pessoas haviam sido forçadas ao deslocamento, entre os quais 25,9 milhôes refugiados (ACNUR, 2019). 
A atual pandemia de Covid-19 vem provocando um deslocamento forçado de populaçôes. O registro mais extremo é o caso da Índia: em 24 de março, o premiê Narendra Modi ordenou um lockdown repentino, que provocou fluxos de migração reversa de centenas de milhares de trabalhadores e suas famílias, que tiveram que caminhar centenas de quilômetros a pé para voltar a seus povoados. A maioria desses trabalhadores são de castas inferiores e minorias étnicas. O lockdown indiano tem produzido caos, desabastecimento, fome e muitas mortes, além de aprofundamento de políticas islamofóbicas do atual governo (DANIYAL, 2020; ECKS, 2020; HRW, 2020).

A migração pode ter impacto negativo direto nas condiçóes de saúde desses indivíduos, através de doenças e agravos como tuberculose, sífilis, hipertensão, diabetes mellitus, obesidade, depressão, ansiedade, transtorno do estresse póstraumático, torturas, mutilações, incluindo mutilações genitais femininas e violência sexual. Em geral, refugiados manifestam ocorrência de doenças infecciosas antes, durante e após a migração forçada (FAERSTEIN; TRAJMAN, 2018).

Roraima, estado brasileiro a receber a maioria dos migrantes forçados vindos da Venezuela, já enfrentava dificuldades de proteção e assistência a essa população por seus serviços de saúde serem deficitários antes mesmo do fluxo migratório venezuelano (BARRETO et al., 2018). Hoje possui ocupaçôes organizadas pelos próprios migrantes e abrigos com milhares de venezuelanos geridos pela Operação Acolhida do exército brasileiro e ONGs (OPERAÇÃO ACOLHIDA, 2020). No município do Rio de Janeiro, por exemplo, sabe-se que refugiados moram geralmente em favelas e periferias, compartilhando moradia com muitas pessoas por domicílio (CAVALCANTE, 2019). Em ambos os casos, o risco de propagação de Covid-19 é alto.

Ao ser deflagrada a pandemia pela Covid-19, novas e antigas preocupaçóes em saúde emergiram. Vulnerabilidades anteriores são agudizadas e a transmissão do vírus em rápida e larga escala nos surpreendem. Neste momento, pesquisadores e entidades multilaterais fazem uma chamada internacional pela saúde de refugiados no esforço em inseri-los na agenda da saúde global de resposta à Covid-19 (KLUGE et al., 2020; EDITORIAL, 2020b). Buscam sensibilizar a comunidade acadêmica e governos a não abandonarem os refugiados na elaboração das estratégias de prevenção e combate à pandemia, mitigando os impactos futuros e em curso. São enfatizadas as condiçốes de transitoriedade, precariedade e superlotação dos abrigos e campos 
de refugiados pelo mundo, que não possuem estrutura sanitária adequada, oferta de assistência em saúde e possibilidade de garantir as medidas de distanciamento social. Mesmo fora dos abrigos, a perda de renda, a recorrente dificuldade de acesso à saúde, a insegurança quanto ao seu status migratório e informações pouco adequadas são outros aspectos sensíveis para refugiados durante a pandemia (OMS, 2020b).

Lugar de trânsito e proteção para muitos sujeitos forçados a migrar, o Brasil não fica de fora dos vários desafios colocados pelo cenário da pandemia para a comunidade de refugiados. De acordo com os dados mais recentes do Comitê Nacional para os Refugiados (CONARE), em 2018 haviam sido reconhecidas 11.231 pessoas refugiadas e 161.057 permaneciam com suas solicitaçóes de refúgio em trâmite; 52\% dessas solicitaçóes são de sujeitos de nacionalidade venezuelana (CONARE, 2019). Destacam-se entre as nacionalidades mais recorrentes nas solicitaçôes e reconhecimentos os nacionais da Venezuela, Síria, República Democrática do Congo, Colômbia, Palestina, Paquistão, Angola, Haiti e Cuba.

\section{Fechamento de fronteiras, direitos e saúde}

Para os indivíduos em busca de refúgio, determinadas medidas resultam em ampliação das dificuldades de acessar a proteção internacional e ter sua saúde preservada. A Organização Internacional de Migraçôes (OIM) e o Alto Comissariado das Naçóes Unidas para Refugiados (ACNUR) suspenderam temporariamente as viagens de reassentamento devido a regulamentaçôes de países para retardar a disseminação da Covid-19; ao mesmo tempo, apelaram aos Estados que as viagens sejam garantidas em casos críticos (ONU, 2020).

Fechamento de fronteiras e regulação de deslocamentos para controlar a pandemia em curso envolvem decisóes políticas. No caso brasileiro, o fechamento de fronteira com a Venezuela ocorreu em março de 2020, decretando a restrição de entrada de estrangeiros procedentes desse país (BRASIL, 2020c). As políticas de fronteira restritivas tendem a fragilizar a saúde de refugiados (CASTIGLIONE, 2018). Paradoxalmente, as alegaçóes oficiais também usaram argumentos de saúde pública para restringir a entrada de estrangeiros pela fronteira Brasil-Venezuela, afirmando que ela se deu por "motivos sanitários relacionados aos riscos de contaminação pelo coronavírus” (BRASIL, 2020c). A restrição ocorreu quando a Venezuela possuía 33 casos importados, enquanto as fronteiras aéreas do Brasil com a Europa 
mantinham-se abertas, mesmo com dezenas de milhares de casos confirmados no continente europeu (OMS, 2020a; BBC, 2020). Restringiu-se a fronteira terrestre, principal forma de travessia de pessoas em busca de proteção e refúgio, ao passo que as fronteiras aéreas, inclusive com a própria Venezuela, permaneciam abertas. A portaria ainda estabeleceu puniçôes: deportação e inabilitação de pedido de refúgio caso o estrangeiro descumpra a restrição (BRASIL, 2020c).

Um dos riscos desse tipo de manobra é a possibilidade de governos imporem um estado de constante vigilância e suspensão dos direitos humanos, tendo na pandemia um novo argumento para redução das liberdades e de direitos - neste caso o direito de buscar refúgio (NAY, 2020). Esse risco fica mais claro ao atentarmos para o processo que levou ao fechamento da fronteira Brasil-Venezuela. $\mathrm{O}$ atual Governo Federal, eleito em fins de 2018, vem modificando radicalmente a política externa brasileira, com o abandono do multilateralismo e episódios que trouxeram incertezas para o campo da migração e refúgio. Essa tendência é ilustrada pela saída do Brasil do Pacto Global para uma Migração Segura, Ordenada e Regular (FAERSTEIN; TRAJMAN, 2019), a Portaria no 666, de 25 de julho de 2019, que retomou o viés securitário para a política de migração, e a decisão do CONARE de cancelar o status de refugiados de três paraguaios em sessão atípica sem presença de representantes da sociedade civil que compóem o colegiado. Aparentemente de forma contraditória aos exemplos acima, em 2019 o CONARE reconheceu "grave e generalizada violação de direitos humanos" na Venezuela, facilitando a obtenção do status de refúgio para venezuelanos. A decisão, no entanto, foi pautada pelo alinhamento ideológico com a oposição ao governo desse país (MOREIRA, 2019).

Apesar do jogo político-ideológico em torno da fronteira, é importante descrever os esforços da Operação Acolhida e do Governo de Roraima, entre outras entidades, para lidar com essa crise migratória e com a pandemia. Até $1^{\circ}$ de junho de 2020, foram contabilizados no estado de Roraima 3.850 casos confirmados e 120 óbitos por Covid-19 (RORAIMA, 2020a). Dentre esses casos, foram registrados entre refugiados venezuelanos 114 casos suspeitos, 27 confirmados e a morte de uma mulher da etnia Warao; também foram divulgados 98 casos confirmados entre militares (RORAIMA EM TEMPO, 2020). Não foram encontrados dados epidemiológicos em sites oficiais da Operação Acolhida sobre refugiados venezuelanos e militares. A Operação Acolhida, iniciativa do Exército para lidar com a migração venezuelana no Brasil inclui, além das Forças Armadas, diversos órgãos do aparato administrativo 
e burocrático brasileiro, organizaçôes internacionais do sistema da ONU, ONGs humanitárias e outras organizaçôes civis (KANAAN; TÁSSIO; SIDMAR, 2018). Em seu bojo, foi elaborado um Plano Emergencial de Contingenciamento para Covid-19 (OPERAÇÃO ACOLHIDA, 2020). O plano visa programar e efetivar ações sanitárias nos abrigos, ocupações e demais atividades da Operação Acolhida. Em paralelo, a Secretaria de Estado da Saúde de Roraima também desenvolveu seu plano de contingência que faz menção à "vulnerabilidade do Estado pela presença de duas fronteiras internacionais (Venezuela e Guiana) e pelo intenso fluxo migratório no território" (RORAIMA, 2020b), mencionando colaboraçóes com a Operação Acolhida e distinção de responsabilidades.

\section{Racismo, xenofobia e o risco sanitário}

No plano estadual de Roraima (RORAIMA, 2020b) e na portaria sobre restrição da entrada de estrangeiros oriundos da Venezuela no Brasil (BRASIL, 2020c), chama a atenção a noção de potencial risco epidemiológico representado pela migração internacional, uma associação questionável quando se trata das migraçôes forçadas. Esse nexo fortalece a xenofobia, como sabemos, a partir das experiências históricas de culpabilização e estigmatização de migrantes ou de minorias étnicas ou religiosas pelas epidemias.

Um marcante e ilustrativo episódio ocorreu com os haitianos, culpabilizados pelo governo dos EUA pela epidemia de HIV-aids, acusação posteriormente desmentida. No Brasil, haitianos passaram por constrangimentos e preconceitos durante a epidemia de ebola que ocorria na África ocidental, mesmo o Haiti sendo um país caribenho (VENTURA; YUJA, 2019). Venezuelanos no Brasil recentemente foram culpabilizados pelo sarampo, ainda que a cepa D8 seja de origem europeia (LAZAR et al., 2019). Com a Covid-19, recai sobre os chineses a força da estigmatização nos jogos geopolíticos (ISTOÉ, 2020). Existindo ou não um nexo epidemiológico, imigrantes e refugiados são recorrentemente associados ao estereótipo do estrangeiro que carrega consigo o perigo sanitário.

O agravamento de casos de violência de motivação racista e xenofóbica contra imigrantes e refugiados se agudiza nessa conjuntura crítica. A retórica de que os estrangeiros subtraem os recursos dos brasileiros, como benefícios governamentais e atendimentos médicos, se populariza $(G 1,2020)$. Nesse contexto, migrantes 
e refugiados são culpabilizados por desigualdades estruturais, apesar de essas comunidades se encontrarem entre os grupos que padecem das desigualdades existentes. A chegada em um novo país pode significar mudanças na qualidade de vida e alívio para as tensôes experienciadas em seus países de origem. Porém, violências recorrentes no país de acolhida repetem-se com os refugiados, sendo racismo e a xenofobia os mais importantes.

Os impactos do racismo na saúde da população negra no Brasil e sua determinação na produção de hierarquia social e iniquidades em saúde têm sido recorrentemente examinados (WERNECK, 2016). Esse racismo recai também sobre refugiados de raça negra, manifesto em dificuldades de estabelecer laços de amizade com brasileiros, de obtenção de empregos formais, nas implicações na saúde mental e na diferenciação entre refugiados brancos e negros. Trata-se de formas de racismo que não necessariamente correspondem ao racismo experimentado em seus países de origem (PEREIRA, 2018).

\section{Informações em saúde e auxílio emergencial}

O acesso a serviços de saúde e benefícios da assistência social são questôes antigas que se tornam mais sensíveis no atual contexto. Vem sendo custoso para muitos brasileiros obter o Auxílio Emergencial, benefício temporário de proteção social que visa amortecer as repercussôes da pandemia, garantindo alimentação e subsistência mínima. Em relação aos grupos imigrantes, barreiras extras vêm se apresentando, incluindo a demanda de documentos de identificação e regularidade migratória (FOLHA DE S. PAULO, 2020). No campo da saúde, a suspeição ou negação de tratamento quando os sujeitos migrantes não portam determinados papéis ou comprovantes, constituem indícios de uma burocratização negligente. Essas barreiras documentais e comprobatórias foram matéria de ofício da Defensoria Pública da União de São Paulo (DELFIM, 2020a) e de carta aberta do Comitê Estadual Intersetorial de Políticas de Atenção aos Refugiados e Migrantes do Rio de Janeiro CEIPARM/RJ (MPF, 2020) para orientação e resolução dessas dificuldades.

Os relatórios e boletins publicados pelo Ministério da Saúde, estados e municípios não apresentam dados desagregados por nacionalidade ou etnia (BRASIL, 2020b). Essa ausência de números sobre nacionalidade nos boletins poderia ser compreensível pela tentativa de evitar a associação entre migração e risco 
epidemiológico, fenômeno recorrente em epidemias. Contudo, a própria obtenção de dados sobre imigrantes e refugiados notificados com suspeita de Covid-19 está prejudicada pela forma de notificação dos casos.

Em âmbito nacional, existem dois sistemas de notificação associados à Covid-19: e-SUS VE (ou e-SUS Notifica), utilizado para notificação de casos de síndrome gripal suspeitos de Covid-19 pelas unidades de saúde públicas e privadas e o SIVEP-Gripe (Sistema de Informação da Vigilância Epidemiológica da Gripe), usado pelas Unidades de Vigilância Sentinela de Síndrome Gripal e os hospitais com internação de casos de síndrome respiratória aguda grave (SRAG) para realizar suas notificaçóes (BRASIL, 2020d). No e-SUS VE, utilizado em maior escala no sistema de saúde, o campo "estrangeiro" aparece apenas quando não é informado o CPF, solicitando, então, país de origem e passaporte (DATASUS, 2020). No SIVEP-Gripe, a notificação não possui campo dedicado a nacionalidade (BRASIL, 2020e). Logo, nenhum dos dois sistemas garante informaçôes sobre nacionalidade. Essa ausência gerou movimento da sociedade civil representada por associaçôes e coletivos dedicados a questôes de migração, solicitando maior atenção aos registros de nacionalidade nos formulários e sistemas de notificação relacionados ao Covid-19 (DELFIM, 2020b).

É importante frisar que os marcadores da diferença em termos de saúde pública, como a nacionalidade, não se restringem a critérios para definição de caso de Covid-19 (ou outras doenças) ou aspectos biológicos (BARATA, 2009). Dados desagregados por nacionalidade podem apoiar os gestores locais na organização das respostas à pandemia considerando as vulnerabilidade e especificidades das populaçôes imigrantes e refugiadas. Caso contrário, reforçaremos a situação de desigualdade em saúde e invisibilidade dessa população.

\section{Considerações finais}

Muitos desafios sanitários e políticos se colocavam antes da deflagração da Emergência de Saúde Pública de Importância Internacional por Covid-19 e se aprofundam agora. Ademais, não há evidências de que um cenário mais favorável para essas populaçôes será inaugurado posteriormente à pandemia. Será necessário um amplo alinhamento dos esforços de pesquisa e intervençôes em seu benefício nas áreas afeitas à saúde global, para mapear impactos e pensar estratégias que efetivem o direito à saúde desses grupos, enfrentando a complexidade que representam para 
gestores e profissionais de saúde. No caso do Brasil, o tratamento da pandemia deve ser entendido como uma intensificação da renúncia do Governo Federal à responsabilidade pela governança da saúde pública, ela própria definida por negação consistente de evidências científicas (CAMARGO; COELI, 2020), disseminação de fake news (ORTEGA; ORSINI, 2020) e congelamento de fundos de saúde pública (BRASIL, 2016). Além disso, embora essa negligência tenha implicaçôes de longo alcance, seus efeitos mais perniciosos estão sendo sentidos entre as comunidades já em situação de marginalização e miséria, a saber, as comunidades negras e indígenas. $\mathrm{O}$ governo por "ignorância seletiva” (McGOEY, 2012) de evidências e conhecimentos em saúde pública e o governo "por exceção" - ou seja, uma forma de governabilidade sem Estado, ou com um Estado ausente (NGUYEN, 2009) - comisturam-se para produzir efeitos devastadores para as comunidades marginalizadas que controla.

Pensar políticas e intervençóes de saúde global para enfrentar a pandemia de Covid-19 em contextos de extrema vulnerabilidade como o dos refugiados exige ir além de políticas públicas, intervenções e medidas de saúde pública de "tamanho único" e de cima para baixo, tão frequentes no campo da saúde global, que desconsideram as condições de vida dos indivíduos para os quais essas medidas são destinadas, e envolver esses grupos em seu desenho e implementação para garantir sua efetividade nesses contextos. Para tanto, são imperativas a análise cuidadosa das especificidades históricas e culturais desses locais e as experiências situadas dos indivíduos para produzir evidências relevantes e intervençóes adequadas para esses grupos (ORTEGA; BEHAGUE, 2020).

Racismo, xenofobia, fronteiras fechadas e experiências concretas são assuntos fundamentais tanto para populaçóes refugiadas, quanto para tantos outros grupos em processo de vulnerabilização durante a pandemia de Covid-19. Por fim, as reflexôes contidas neste texto buscaram estimular debate amplo e multifacetado, no intuito de contribuir com esse esforço de conhecer e mitigar os impactos da pandemia entre refugiados.

\section{Referências}

ALTO COMISSARIADO DAS NAÇÓES UNIDAS PARA OS REFUGIADOS. Global Trends: forced displacement in 2018. ACNUR, Genebra, 2019a. Disponível em: <https://www. unhcr.org/statistics/unhcrstats/5d08d7ee7/unhcr-global-trends-2018.html>. Acesso em: 25 maio 2020 . 
Protocolo de 1967 relativo ao estatuto dos refugiados. ACNUR, Genebra, 1967. Disponível em: <https://www.acnur.org/fileadmin/Documentos/portugues/BD_Legal/ Instrumentos_Internacionais/Protocolo_de_1967.pdf>. 25 maio 2020.

BARATA, R. B. Como e por que as desigualdades sociais fazem mal à saúde. Rio de Janeiro: Editora Fiocruz, 2009.

BARRETO, T. M. A. C. et al. Os impactos nos serviços de saúde decorrentes da migração venezuelana em Roraima: ensaio reflexivo. In: BAENINGER, R. et al. (Orgs.). Migraçôes Venezuelanas. Campinas: Núcleo de Estudos de População "Elza Berquó” - Nepo/Unicamp, 2018. p. 369-373.

BBC. Coronavirus: Brasil fecha quase toda a fronteira terrestre, mas mantém entrada por aeroportos. Brasil, 2020. Disponível em: <https://www.bbc.com/portuguese/brasil-51966428>. Acesso em: 26 maio 2020.

BRASIL. Casa Civil. Emenda Constitucional no 95, de 15 de dezembro de 2016. Altera o Ato das Disposições Constitucionais Transitórias, para instituir o Novo Regime Fiscal, e dá outras providências. Brasília: Governo Federal, 2016. Disponível em: <http://www.planalto.gov.br/ ccivil_03/constituicao/emendas/emc/emc95.htm>. Acesso em: 30 maio 2020.

. Ministério da Justiça e Segurança Pública. Portaria no 666, de julho de 2019. Dispóe sobre o impedimento de ingresso, a repatriação e a deportaçáo sumária de pessoa perigosa ou que tenha praticado ato contrário aos princípios e objetivos dispostos na Constituição Federal. Brasília: MJSP, 2019. Disponível em: <http:/www.in.gov.br/en/web/dou/-/portaria-n-666-de25-de-julho-de-2019-207244569>. Acesso em: 26 maio 2020.

. Ministério da Saúde. Boletins Epidemiológicos. Brasília: MS, 2020b. Disponível em: <https://coronavirus.saude.gov.br/boletins-epidemiologicos>. Acesso em: 1º jun. 2020.

Ministério da Saúde. Ficha de registro individual - Casos de sindrome respiratória aguda grave hospitalizado. SIVEP-Gripe. Brasília: MS, 2020e. Disponível em: <https://egestorab.saude.gov.br/image/?file=20200429_N_ FichaSIVEPGRIPESRAGHospital31032020_8248374246976398791.pdf>. Acesso em: $1^{\circ}$ jun. 2020.

- Ministério da Saúde. Guia de Vigilância Epidemiológica Emergência de Saúde Pública de Importância Nacional pela Doença pelo Coronavirus 2019. Brasília: MS, 2020d. Disponível em: <https://www.saude.gov.br/images/pdf/2020/April/06/GuiaDeVigiEp-final.pdf>. Acesso em: 28 maio 2020.

. Ministério da Saúde. Portaria no 120, de 17 de março de 2020. Dispóe sobre a restrição excepcional e temporária de entrada no País de estrangeiros oriundos da República Bolivariana da Venezuela, conforme recomendação da Agência Nacional de Vigilância Sanitária. Brasília: MS, 2020c. Disponível em: <http://www.in.gov.br/en/web/dou/-/portaria-n-120-de-17-demarco-de-2020-248564454>. Acesso em: 25 maio 2020. 
. Ministério da Saúde. Portaria no 188, de 3 de fevereiro de 2020. Declara Emergência em Saúde Pública de importância Nacional (ESPIN) em decorrência da Infecção Humana pelo novo Coronavírus. Brasília: MS, 2020a. Disponível em: <http://www.in.gov.br/web/dou/-/ portaria-n-188-de-3-de-fevereiro-de-2020-241408388>. Acesso em: 25 maio 2020.

CAmargO, K. R.; COELI, C. M. A difícil tarefa de informar. Physis. Revista de Saúde Coletiva, v. 30, n. 2, p. 1-5, 2020. Disponível em: <https:/www.ims.uerj.br/wp-content/ uploads/2020/04/physis30_2_a03.pdf>. Acesso em: 30 maio 2020.

CASTIGLIONE, D. P. Políticas de fronteiras e saúde de populaçóes refugiadas. Cad. Saúde Pública, Rio de Janeiro, v. 34, n. 4, e00006018, 2018. Disponível em: <https://doi. org/10.1590/0102-311X00006018 >. Acesso em: 25 maio 2020.

CAVALCANTE, J. R. Perfil, trajetórias e saúde de solicitantes de refúgio atendidos pela Cáritas Arquidiocesana do Rio de Janeiro entre 2016 e 2017. 2019. 106 f. Dissertação (Mestrado em Saúde Coletiva) - Instituto de Medicina Social, Universidade do Estado do Rio de Janeiro, Rio de Janeiro, 2019. Disponível em: <https://pesquisa.bvsalud.org/portal/resource/pt/biblio-998967>. Acesso em: 26 maio 2020.

CAVALCANTE, J.R.; SCHUTZ, G. E. A epidemia de doença pelo vírus Ebola de 2014: o Regulamento Sanitário Internacional na perspectiva da Declaração Universal dos Direitos Humanos. Cadernos Saúde Coletiva, Rio de Janeiro, v. 24, n. 2, p. 242-247, jul. 2016. Disponível em: < https://doi.org/10.1590/1414-462X201600020184 >. Acesso em: 25 maio 2020.

COMITE NACIONAL PARA REFUGIADOS CONARE, 2019. Refúgio em Números. Brasília: Ministério da Justiça, 2019. Disponível em: <https://www.justica.gov.br/seus-direitos/ refugio/refugio-em-numeros>. Acesso em: 25 maio 2020.

DANIYAL, S. Not China, not Italy: India's coronavirus lockdown is the harshest in the world. Schroll.in. 3 abr. 2020. Disponível em: <https://scroll.in/article/957564/not-china-not-italyindias-coronavirus-lockdown-is-the-harshest-in-the-world>. Acesso em: 28 maio 2020.

DATASUS. Tutorial de navegação do Sistema de Notificação do Ministério da Saúde e-SUS NOTIFICA. Brasília: Ministério da Saúde, 2020. Disponível em: <https://datasus.saude. gov.br/wp-content/uploads/2020/05/Tutorial-de-Navega\%C3\%A7\%C3\%A3o-e-SUS-VE_ atualizado-19-05.pdf >. Acesso em: $1^{\circ}$ jun. 2020.

DELFIM, R. B. 2020. Ofício da DPU dá suporte a imigrantes indocumentados para recebimento do auxílio emergencial. MigraMundo, São Paulo, 2020a. Disponível em: <https://www. migramundo.com/oficio-da-dpu-da-suporte-a-imigrantes-indocumentados-para-recebimentodo-auxilio-emergencial/>. Acesso em: 27 maio 2020.

DELFIM, R. B. Associaçôes e imigrantes pedem inclusão de nacionalidade nos registros do Ministério da Saúde. MigraMundo, São Paulo, 2020b. Disponível em: <https://www. migramundo.com/associacoes-e-imigrantes-pedem-inclusao-de-nacionalidade-nos-registrosdo-ministerio-da-saude/>. Acesso em: 27 maio 2020. 
ECKS, S. Lockdowns save, lockdowns kill: Valuing life after coronashock. Somatosphere. Series: Dispatches from the pandemic. 24 abr. 2020. Disponível em: <http://somatosphere.net/2020/ lockdowns-save-lockdowns-kill-valuing-life-after-coronashock.html/>. Acesso em: 30 maio 2020. EDITORIAL. Covid-19 will not leave behind refugees and migrants. The Lancet, v. 395, n. 10230, p. 1090, abr. 2020b. Disponível em: <https://doi.org/10.1016/S0140-6736(20)307583>. Acesso em: 24 maio 2020.

EDITORIAL. Redefining vulnerability in the era of Covid-19. The Lancet, 395, n. 10230, P1089, 4 abr. 2020a. Disponível em: <https://doi.org/10.1016/S0140-6736(20)30757-1>. Acesso em: 24 maio 2020.

FAERSTEIN, E.; TRAJMAN, A. Forced Migration and Health: Problems and Responses. In: PARKE, R.; GARCÍA, J. (Orgs.). Routledge Handbook on the Politics of Global Health. 1ed.New York: Routledge Handbook, 2018, v. 1, p. 359-367.

FAERSTEIN, E.; TRAJMAN, A. Por que o Brasil deve retornar ao Pacto Global para Migração Segura, Ordenada e Regular. Observatório do Amanhã, 2019. Disponível em: <https:// museudoamanha.org.br/pt-br/artigo-por-que-o-brasil-deve-retornar-ao-pacto-global-paramigracao-segura-ordenada-e-regular>. Acesso em: 25 maio 2020.

FOLHA DE S. PAULO. Caixa barra pagamento de auxílio emergencial a imigrantes. São Paulo, 2020. Disponível em: <https://www1.folha.uol.com.br/mercado/2020/05/caixa-barrapagamento-de-auxilio-emergencial-a-imigrantes.shtml>. Acesso em: 25 maio 2020.

FREITAS, P. DE S. S. et al. Síndrome congênita do vírus Zika: perfil sociodemográfico das mães. Revista Panamericana de Salud Pública, v. 43, p. 1, 19 mar. 2019. Disponível em: <https:// iris.paho.org/handle/10665.2/49776>. Acesso em: 24 maio 2020.

G1. Angolano morre esfaqueado na Zona Leste de SP e 2 ficam feridos; imigrantes deixam suas casas em Itaquera por medo de xenofobia. São Paulo, 2020. Disponível em: <https://g1.globo. com/sp/sao-paulo/noticia/2020/05/19/angolano-morre-esfaqueado-na-zona-leste-de-sp-e-2ficam-feridos-imigrantes-deixam-suas-casas-em-itaquera-por-medo-de-xenofobia.ghtml>. Acesso em: 27 maio 2020.

HRW. India: Covid-19 Lockdown Puts Poor at Risk. Human Rights Watch, 27 mar. 2020. Disponível em: <https://www.hrw.org/news/2020/03/27/india-Covid-19-lockdown-puts-poorrisk>. Acesso em: 29 maio 2020.

ISTOÉ. A xenofobia contra os chineses. São Paulo, 2020. Disponível em: <https://istoe.com.br/axenofobia-contra-os-chineses/>. Acesso em: 26 maio 2020

KANAAN, C.; TÁSSIO, M.; SIDMAR. As ações do Exército Brasileiro na ajuda humanitária aos imigrantes venezuelanos. In.: ZUBEN et al. (Org.). Migrações Venezuelanas. Campinas: Núcleo de Estudos de População "Elza Berquó” - Nepo/Unicamp, 2018. 
KENNEDY, D. M. et al. Modeling the effects of intervention strategies on Covid-19 transmission dynamics. Journal of Clinical Virology, v. 128, p. 104440, jul. 2020. Disponível em: <https://pubmed.ncbi.nlm.nih.gov/32425658/>. Acesso em: 27 maio 2020.

KLUGE, H. H. P. et al. Refugee and migrant health in the Covid-19 response. The Lancet, v. 395, n. 10232, p. 1237-1239, abr. 2020. Disponível em: <https://doi.org/10.1016/S01406736(20)30791-1>. Acesso em: 24 maio 2020.

LAZAR, M. et al. Characterisation of measles after the introduction of the combined measlesmumps-rubella (MMR) vaccine in 2004 with focus on the laboratory data, 2016 to 2019 outbreak, Romania. Eurosurveillance, v. 24, n. 29, 18 jul. 2019. Disponível em: <https://doi. org/10.2807/1560-7917.ES.2019.24.29.1900041>. Acesso em: 25 maio 2020.

MCGOEY, L. Strategic unknowns: towards a sociology of ignorance. Economy and Society, v. 41, n. 1, p. 1-16, 2012. Disponível em: <https://doi.org/10.1080/03085147.2011.637330 >. Acesso em: 29 maio 2020.

MILESI, R. Refugiados e Migraçôes Forçadas: uma Reflexão aos 20 Anos da Declaração de Cartagena. Brasília: Instituto Migraçôes e Direitos Humanos, 2005. Disponível em: <https://www.justica.gov.br/central-de-conteudo/estrangeiros/art_irmarosita.pdf>. Acesso em: 27 maio 2020.

MOREIRA, J. B. Migrações internacionais e refúgio sob a ótica do governo Bolsonaro. Revista Mundorama, Brasil, 2019. Disponível em: <https://mundorama.net/?p=26743>. Acesso em: 24 maio 2020.

MINISTÉRIO PÚBLICO FEDERAL. MPF e Comitê de atenção à refugiados propóem estratégias de proteção social durante a pandemia do novo coronavírus no Rio de Janeiro. Brasília: MPF, 2020. Disponível em: <http://www.mpf.mp.br/rj/sala-de-imprensa/noticias-rj/mpf-ecomite-de-atencao-a-refugiados-propoem-estrategias-de-protecao-social-durante-a-pandemiado-novo-coronavirus-no-rio-de-janeiro>. Acesso em: 26 maio 2020.

NAY, O. Can a virus undermine human rights? The Lancet Public Health, v. 5, n. 5, p. e238-e239, maio 2020. Disponível em: <https://pubmed.ncbi.nlm.nih.gov/32325013/>. Acesso em: 25 maio 2020.

NGUYEN, V. K. Government-by-exception: Enrolment and experimentality in mass HIV treatment programmes in Africa. Social Theory \& Health, v. 7, n. 3, p. 196-217, 2009. Disponível em: <https://doi.org/10.1057/sth.2009.12>. Acesso em: 26 maio 2020.

OPERAÇÃO ACOLHIDA. Plano Emergencial de Contingenciamento para Covid-19. Brasília, 2020. Disponível em: <http://www.eb.mil.br/web/noticias/noticiario-do-exercito/-/asset_ publisher/MjaG93KcunQI/content/id/11340193>. Acesso em: 31 maio 2020. 
ORGANIZAÇÃO DAS NAÇÓES UNIDAS. Covid-19: Agencies temporarily suspend refugee resettlement travel. 2020. Disponível em: <https://news.un.org/en/story/2020/03/1059602>. Acesso em: 24 maio 2020.

ORGANIZAÇÃO MUNDIAL DA SAÚDE. Coronavirus disease 2019 (Covid-19) Situation Report. 2020a. Disponível em: < https://www.who.int/emergencies/diseases/novelcoronavirus-2019/situation-reports>. Acesso em: 01 jun. 2020.

Preparedness, prevention and control of coronavirus disease (Covid-19) for refugees and migrants in non-camp settings: interim guidance, 17 April 2020. [s.1.] World Health Organization, 2020b. Disponível em: <https:/apps.who.int/iris/handle/10665/331777.>. Acesso em: 25 maio 2020.

ORTEGA, F; BEHAGUE, D. O que a medicina social latino-americana pode contribuir para os debates globais sobre as políticas da Covid-19: liçóes do Brasil. Physis. Revista de Saúde Coletiva, v. 30, n. 2, e300205, 2020. Disponível em: <https:/www.ims.uerj.br/wp-content/ uploads/2020/04/physis30_2_a05.pdf>. Acesso em: 30 maio 2020.

ORTEGA, F.; ORSINI, M. Governing Covid in Brazil: Dissecting the Ableist and Reluctant Authoritarian. Somatosphere, Series: Dispatches from the pandemic. 17 abr. 2020. Disponível em: <http://somatosphere.net/2020/governing-Covid-in-brazil-dissecting-the-ableist-andreluctant-authoritarian.html/>. Acesso em: 30 maio 2020.

PEREIRA, A. B. O refúgio do trauma. Notas etnográficas sobre trauma, racismo e temporalidades do sofrimento em um serviço de saúde mental para refugiados. REMHU: Revista Interdisciplinar da Mobilidade Humana, v. 26, n. 53, p. 79-97, ago. 2018. Disponível em: < https://doi.org/10.1590/1980-85852503880005306 >. Acesso em: 24 maio 2020.

RORAIMA. Boletim epidemiológico. Boa Vista, 2020a. Disponível em: <https://www.saude.rr.gov. br/index.php/informacoesx/coronavirus/informacoes-coronavirus>. Acesso em: 01 jun. 2020.

RORAIMA. Plano de Contingência do Estado de Roraima para Enfrentamento da Doença pelo Coronavírus 2019 (Covid-19). Boa Vista: SES, 2020b. Disponível em: <https://saude.rr.gov. br/index.php/informacoesx/coronavirus/plano-de-contingencia-estadual/file/1053-plano-decontingencia-estadual-do-coronavirus-2020-2-versao>. Acesso em: 30 maio 2020.

RORAIMA EM TEMPO. Operação acolhida tem 17 venezuelanos recuperados do coronavírus. Disponível em: <https://roraimaemtempo.com/ultimas-noticias/operacao-acolhida-tem-17venezuelanos-recuperados-do-coronavirus-,357892.jhtml>. Acesso em: $1^{\circ}$ jun. 2020.

VENTURA, D.; YUJA, V. Q. Saúde de migrantes e refugiados. Rio de Janeiro: Editora Fiocruz; 2019.

WERNECK, J. Racismo institucional e saúde da população negra. Saúde e Sociedade, v. 25, n. 3, p. 535-549, set. 2016. Disponível em: <https://doi.org/10.1590/s0104-129020162610>. Acesso em: 26 maio 2020. 